Supporting Information for

\title{
Electrospun Poly(acrylic acid)/Silica Hydrogel Nanofibers Scaffold for Highly Efficient Adsorption of Lanthanide Ions and Its Photoluminescence Performance
}

By Min Wang, Xiong Li, Weikang Hua, Lingdi Shen, Xufeng Yu, and Xuefen Wang*

State Key Laboratory for Modification of Chemical Fibers and Polymer Materials, Donghua University, Shanghai 201620, PR China

*Corresponding author: wangxf@dhu.edu.cn 
S1. The morphology of cross-linked PAA-S nanofibers with different silica content in the precursor solutions and after immersing into water
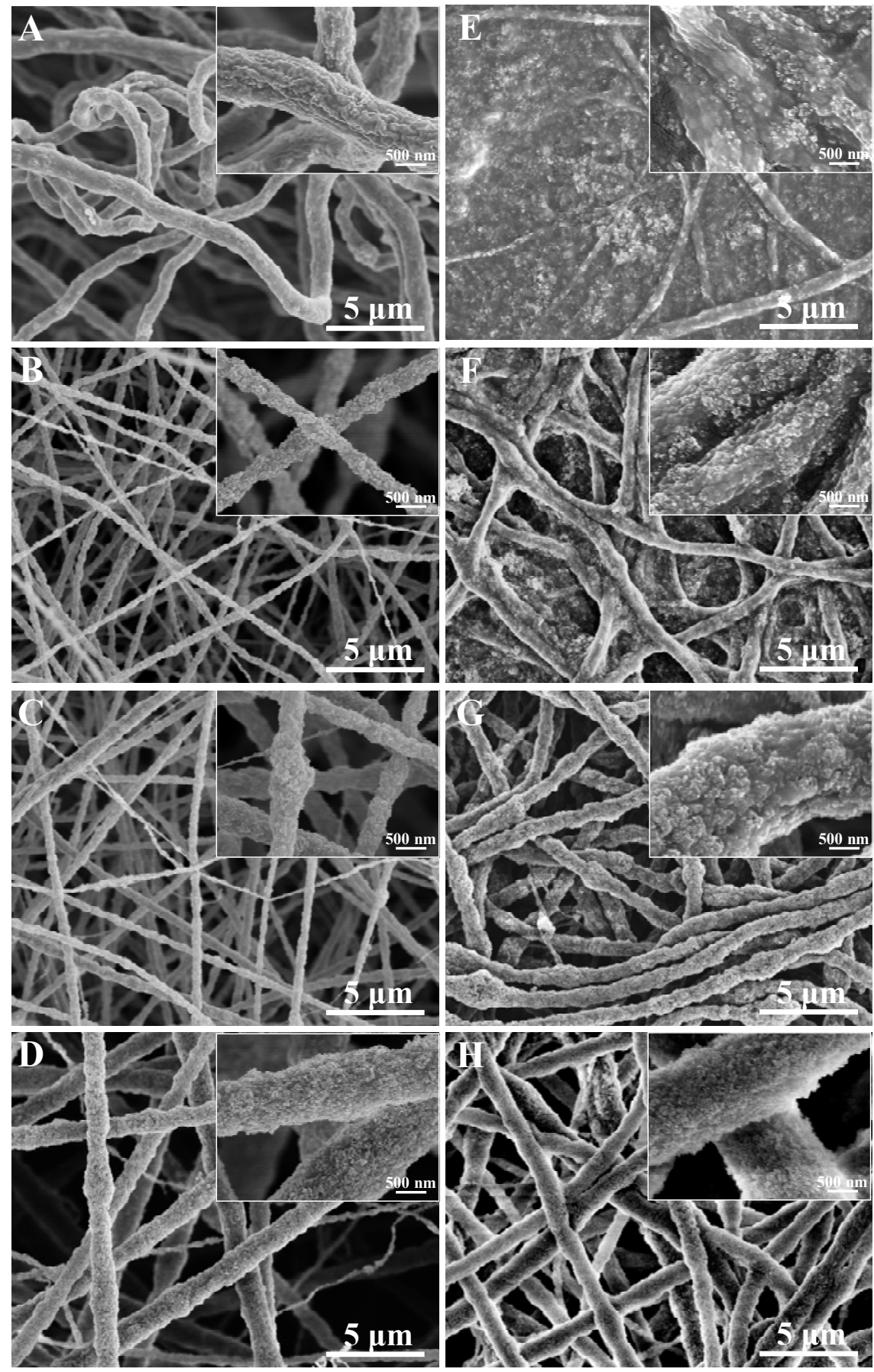

Figure S1. FE-SEM images of cross-linked PAA-S nanofibers with different silica content in the precursor solutions $(\mathrm{A}, \mathrm{E})$ 1.7, $(\mathrm{B}, \mathrm{F}) 3.3,(\mathrm{C}, \mathrm{G}) 5.0$ and $(\mathrm{D}, \mathrm{H}) 6.7 \mathrm{wt} \%$ before $(\mathrm{A}-\mathrm{D})$ and after (E-H) immersing into water (thermal treatment at $150{ }^{\circ} \mathrm{C}$ for $5 \mathrm{~h}$ ). 
S2. The morphology of cross-linked PAA-S nanofibers with different cross-linking time after immersing into water
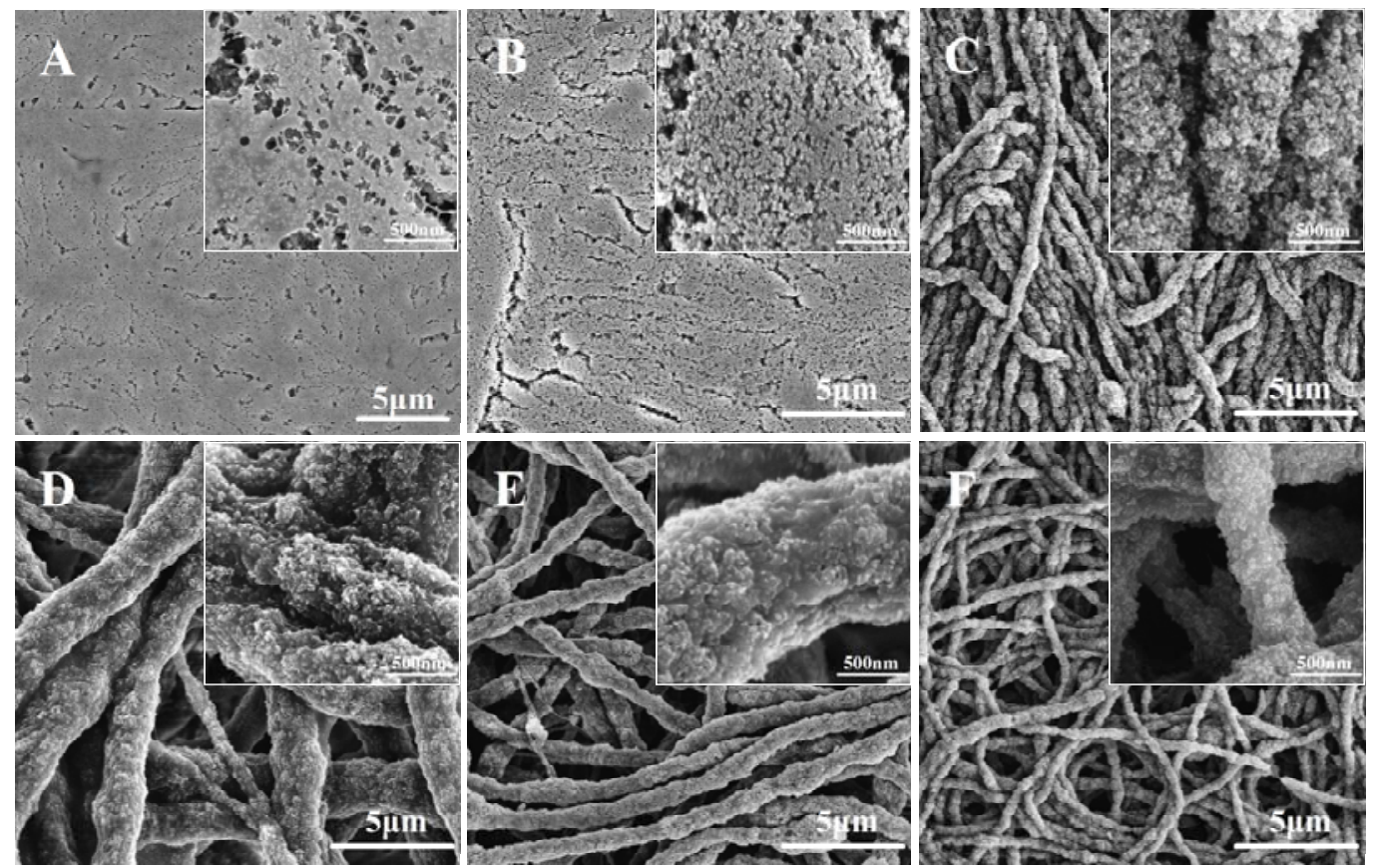

Figure S2. FE-SEM images of cross-linked PAA-S nanofibers with different cross-linking time of (A) 1, (B) 2, (C) 3, (D) 4, (E) 5 and (F) $6 \mathrm{~h}$ after immersing into water (electrospun from the optimal solution with $5.0 \mathrm{wt} \% \mathrm{SiO}_{2}$ content in the precursor solution, thermal treatment at $\left.150{ }^{\circ} \mathrm{C}\right)$. 


\section{S3. Thermal cross-linking mechanism of $\mathrm{PAA} / \mathrm{SiO}_{2}$ hydrogel nanofiber}

FT-IR spectral analysis was employed to confirm the surface chemical compositions of the non-cross-linked and cross-linked PAA-S nanofibers. As shown in Figure S3, the strong broad band ranging from $3428 \mathrm{~cm}^{-1}$ to $3167 \mathrm{~cm}^{-1}$ (OH stretching vibration), the peak at around 2954 $\mathrm{cm}^{-1}\left(\mathrm{CH}\right.$ stretching vibration in $\mathrm{CH}$ and $\left.\mathrm{CH}_{2}\right),{ }^{1} 1710 \mathrm{~cm}^{-1}(\mathrm{C}=\mathrm{O}$ stretching $), 1416 \mathrm{~cm}^{-1}$ (symmetric $\mathrm{COO}^{-}$stretching), ${ }^{2} 1097 \mathrm{~cm}^{-1}$ (Si-O-Si stretching) and $806 \mathrm{~cm}^{-1}$ (Si-O stretching) ${ }^{1}$ were observed for the non-cross-linked nanofibers, while the cross-linked sample exhibited a similar characteristic absorption peak, revealing that the chemical compositions of the nanofibers were essentially maintained after cross-linking.

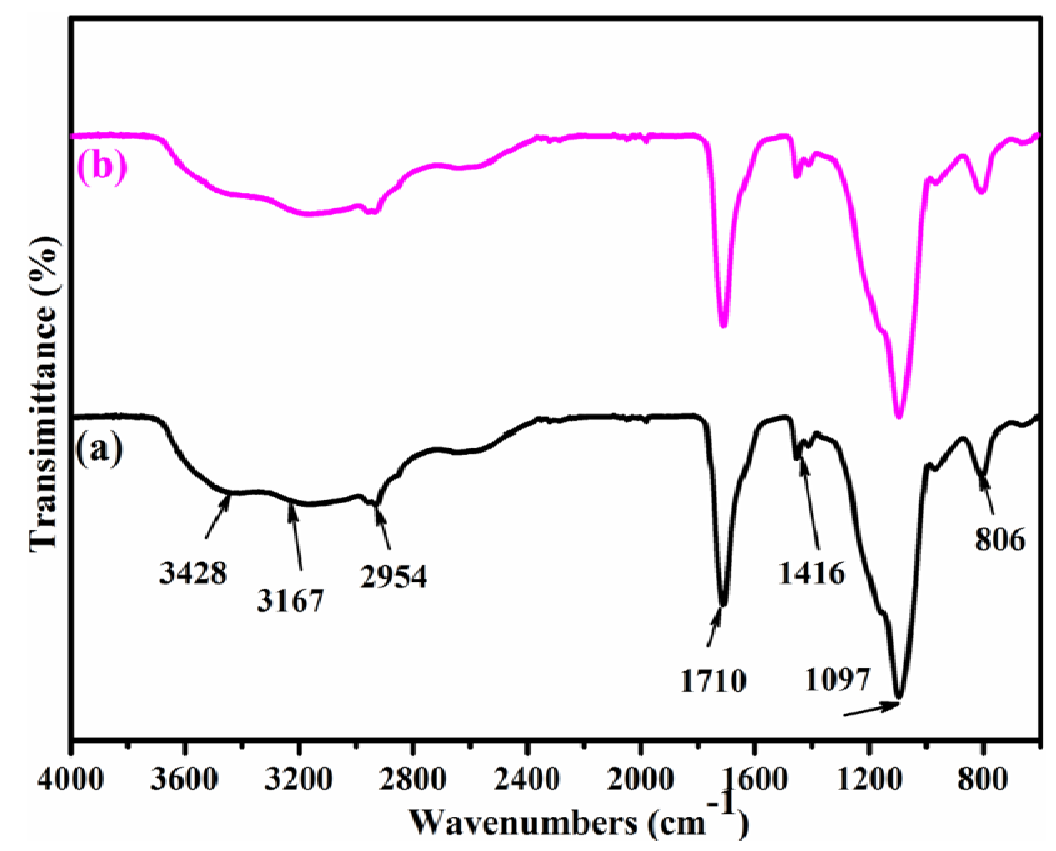

Figure S3. FT-IR spectra of (a) non-cross-linked and (b) cross-linked PAA-S nanofibers. 


\section{S4. Adsorption isotherm}

The Langmuir model assumes that the monolayer adsorption occurred uniformly on a homogeneous surface containing a finite number of identical adsorption sites. ${ }^{3}$ While, Freundlich isotherm model is an empirical equation which can be used to describe a reversible adsorption on an energetically heterogeneous surface with a non-uniform distribution of active sites, and it predicts that the adsorption capacity onto the adsorbents will increase as long as the adsorbate concentration increases. ${ }^{4}$ This two widely used isotherm models can be expressed by the following equations: ${ }^{3}$

Langmuir isotherm

$$
C_{e} / q_{e}=C_{e} / q_{0}+1 / K_{L} q_{0}
$$

Freundlich isotherm

$$
\ln q_{e}=\ln K_{F}+\ln C_{e} / n
$$

Where $\mathrm{q}_{\mathrm{e}}$ is the equilibrium adsorption capacity of $\mathrm{Ln}^{3+}(\mathrm{mg} / \mathrm{g}), \mathrm{C}_{\mathrm{e}}$ is the equilibrium concentration of $\mathrm{Ln}^{3+}(\mathrm{mg} / \mathrm{L})$, and $\mathrm{q}_{0}$ expresses the theoretical maximum adsorption capacity of $\mathrm{Ln}^{3+}(\mathrm{mg} / \mathrm{g}) . \mathrm{K}_{\mathrm{L}}$ is the Langmuir constant $(\mathrm{L} / \mathrm{mg})$ related to the binding energy of adsorption, $\mathrm{K}_{\mathrm{F}}$ is the constant depicting adsorption capacity related to bond strength and the slope $1 / \mathrm{n}$ is a measure of the adsorption intensity or surface heterogeneity.

Additionally, the D-R isotherm model is employed to describe the adsorption on both homogenous and heterogeneous surface and then to estimate the adsorption mechanism. ${ }^{5}$ The equation of the D-R model is expressed as the following equations: 
$\ln q_{e}=\ln q_{D R}-\beta \varepsilon^{2}$

$E=1 / \sqrt{2 \beta}$

Where $\varepsilon$ is the Polanyi potential, which is equal to $\varepsilon=R T \ln \left(1+1 / C_{e}\right), \mathrm{R}$ and $\mathrm{T}$ are the gas constant $(8.314 \mathrm{~J} / \mathrm{mol} \cdot \mathrm{K})$ and the absolute temperature $(\mathrm{K})$, respectively, $\mathrm{q}_{\mathrm{e}}$ and $\mathrm{q}_{\mathrm{DR}}$ are the equilibrium and maximum adsorption capacity of $\mathrm{Ln}^{3+}$, respectively. $\beta$ is a $\mathrm{D}-\mathrm{R}$ isotherm constant correlated to the mean free energy of adsorption $\left(\mathrm{mol}^{2} / \mathrm{J}^{2}\right)$, and $\mathrm{E}(\mathrm{J} / \mathrm{mol})$ is defined as the adsorption energy of which per molecule of the adsorbate transferred from solution to solid surface. What is more, the value of E can be used to estimate the type of the sorption mechanisms. Physisorption processes have adsorption energy (E) in the range of 1.0-8.0 kJ/mol, and the adsorption behavior proceeds by chemisorption when E exceeds $8.0 \mathrm{~kJ} / \mathrm{mol}^{5}$ 

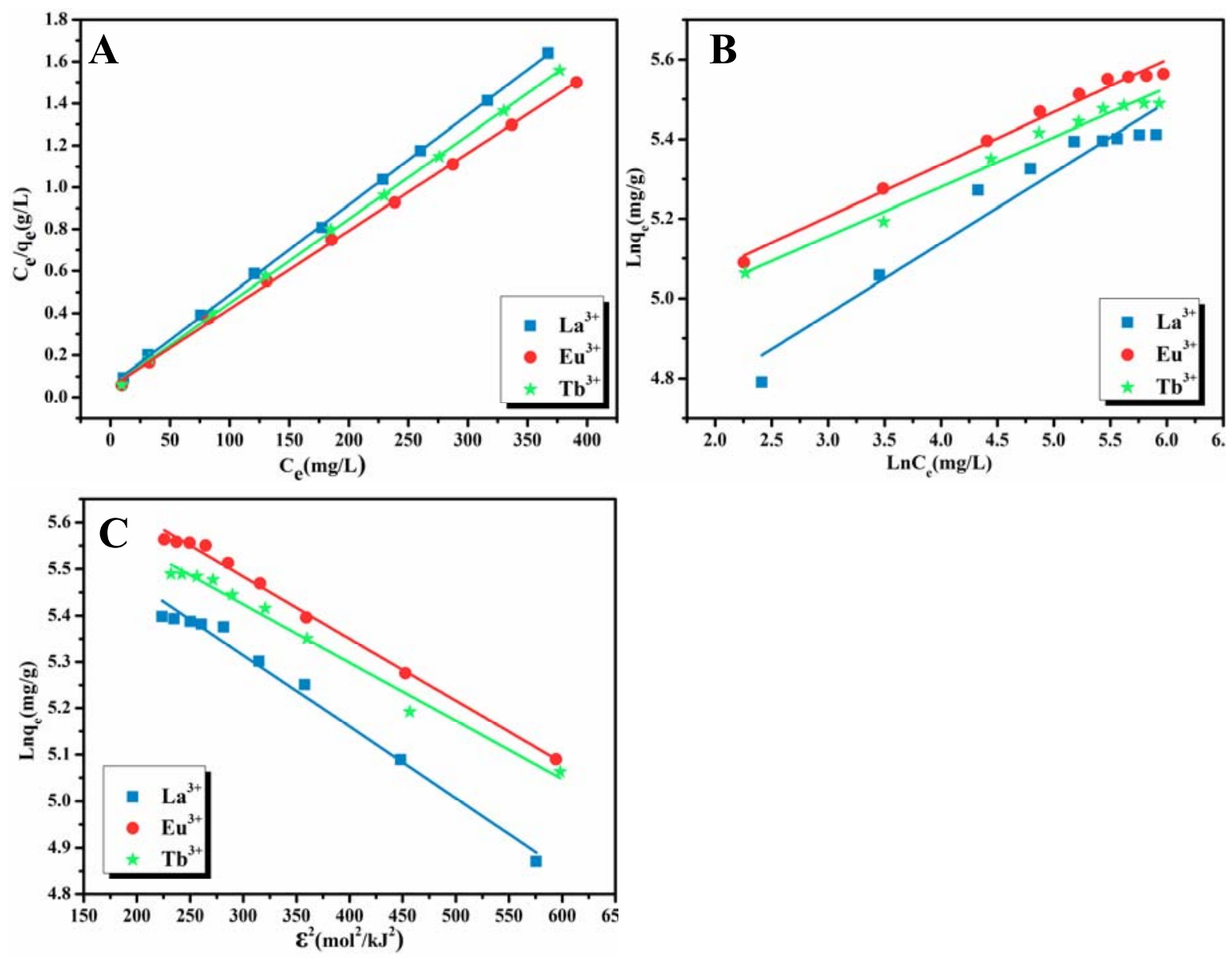

Figure S4. Adsorption isotherms of (A) Langmuir, (B) Freundlich and (C) D-R model for the adsorption of $\mathrm{Ln}^{3+}$ onto PAA-S HNFs. 


\section{S5. Adsorption kinetics}

Three conventional kinetic models of pseudo-first-order (pfo), pseudo-second-order (pso) ${ }^{6}$ and intraparticle diffusion models were used to explore the adsorption kinetics behavior as expressed in eqs (S5), (S6) and (S7), respectively.

$$
\begin{aligned}
& \ln \left(q_{e}-q_{t}\right)=\ln q_{e}-k_{1} t \\
& t / q_{t}=1 / k_{2} q_{e}^{2}+t / q_{e} \\
& q_{t}=K_{p} t^{1 / 2}+C
\end{aligned}
$$

where $\mathrm{q}_{\mathrm{t}}$ and $\mathrm{q}_{\mathrm{e}}(\mathrm{mg} / \mathrm{g})$ are the adsorption amount of $\mathrm{Ln}^{3+}$ at an arbitrary time $\mathrm{t}$ and equilibrium time, $\mathrm{k}_{1}\left(\mathrm{~h}^{-1}\right), \mathrm{k}_{2}\left(\mathrm{~g} \cdot \mathrm{mg}^{-1} \cdot \mathrm{h}^{-1}\right)$ and $\mathrm{K}_{\mathrm{p}}\left(\mathrm{g} \cdot \mathrm{mg}^{-1} \cdot \mathrm{h}^{-0.5}\right)$ are the pseudo-first-model rate constant, the pseudo-second-model rate constant and the intraparticle diffusion rate constant, $\mathrm{C}$ is a constant that related to the effect of boundary layer thickness.

Actually, the adsorption process of an absorbent usually includes three main stages: film or external diffusion which means the diffusion of the metal ions through the boundary layer to the adsorbent surface; transport of the metal ions from the surface to the interior of the adsorbent and called intraparticle diffusion or inner diffusion; adsorption onto the active sites. ${ }^{7}$ Thus, the adsorption rate is also affected by the absorbate transport, which is characterized by either the sole intraparticle diffusion or the combination of film diffusion and intraparticle diffusion. ${ }^{4}$ 

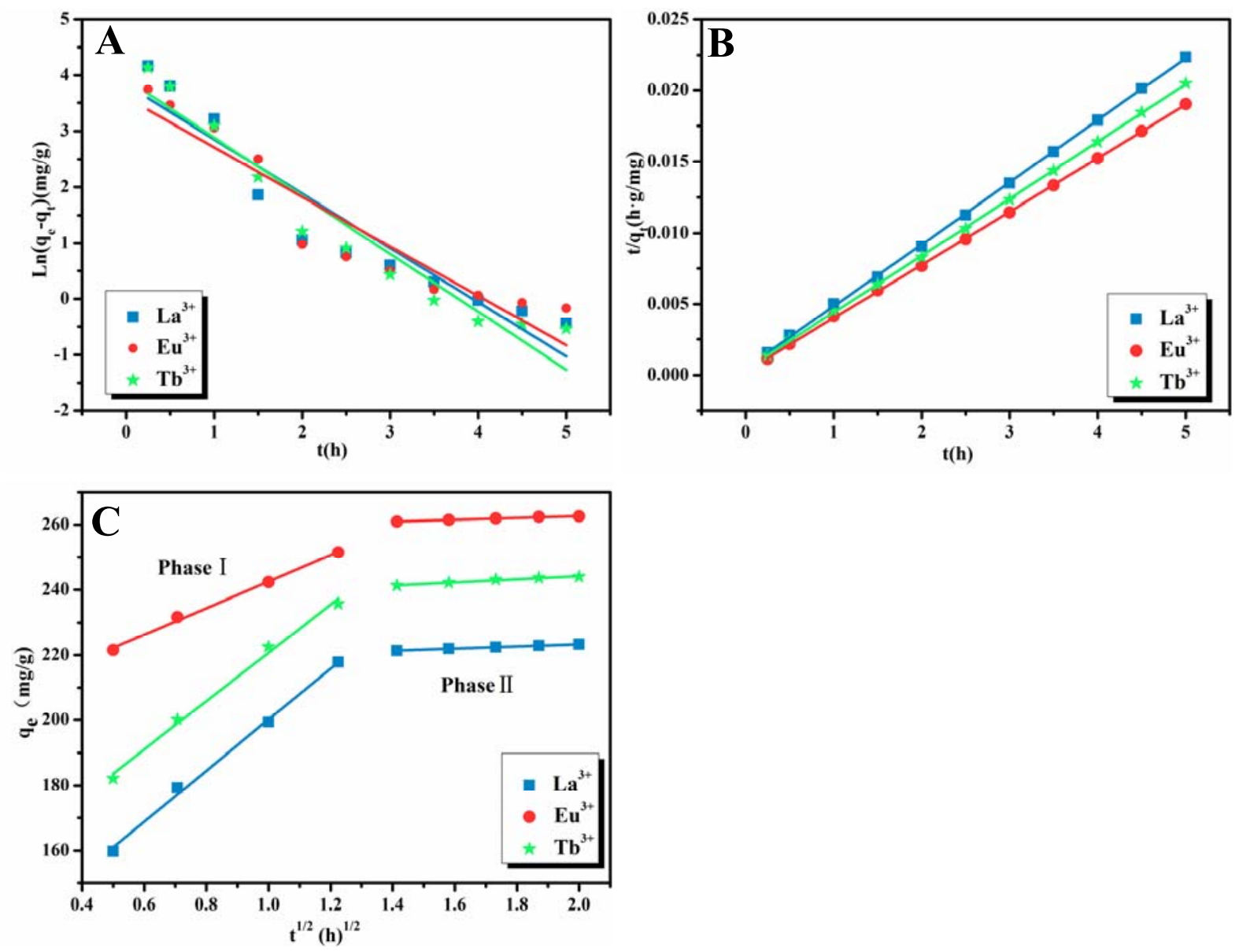

Figure S5. Adsorption kinetics of (A) Pseudo-first-order, (B) Pseudo-second-order and (C) Intraparticle diffusion model for the adsorption of $\mathrm{Ln}^{3+}$ onto PAA-S HNFs. 


\section{S6. Adsorption mechanism}

Figure $\mathrm{S} 6$ presented the core-level spectra of $\mathrm{La} 3 \mathrm{~d}, \mathrm{Eu} 4 \mathrm{~d}$ and $\mathrm{Tb} 4 \mathrm{~d}$. As can be seen from Figure S6A, a doublet peaks were observed at 852.06 and $835.29 \mathrm{eV}$ with a spin-orbit splitting of $16.8 \mathrm{eV}$, which were assigned to $\mathrm{La} 3 \mathrm{~d}_{3 / 2}$ and $\mathrm{La} 3 \mathrm{~d}_{5 / 2}$, respectively. ${ }^{8}$ Similarly, the Eu $4 \mathrm{~d}$ spectra (as shown in Figure S6B) exhibited the binding energy of $\mathrm{Eu} 4 \mathrm{~d}_{3 / 2}$ and $\mathrm{Eu} 4 \mathrm{~d}_{5 / 2}$ at 140.10 and $134.43 \mathrm{eV}$, respectively, which could be contributed to the multiplet structure of the trivalent $4 \mathrm{~d} 4 \mathrm{f} 6$ configurations, and the corresponding spin-orbit splitting of $4 \mathrm{~d}_{3 / 2}$ and $4 \mathrm{~d}_{5 / 2}$ levels was 5.67 $\mathrm{eV}^{9-10}$ In the case of the $\mathrm{Tb} 4 \mathrm{~d}$ core level spectrum (Figure S6C), the strong peak at about 148.24 $\mathrm{eV}$ could be assigned to the binding energy of Tb4d. ${ }^{11-12}$ Moreover, the satellite lines on the high binding energy side of the La3d levels ( 855.18 and $838.43 \mathrm{eV}$ for $3 \mathrm{~d}_{3 / 2}$ and $3 \mathrm{~d}_{5 / 2}$, respectively), Eu $4 \mathrm{~d}$ levels (141.58 and $135.89 \mathrm{eV}$ for $4 \mathrm{~d}_{3 / 2}$ and $4 \mathrm{~d}_{5 / 2}$, respectively) and $\mathrm{Tb} 4 \mathrm{~d}$ level $(154.28 \mathrm{eV}$ for $4 d)$ might be interpreted in terms of the $O(2 p) \rightarrow \operatorname{Ln}(4 f)$ charge-transfer excitation, indicating the formation of Ln-O bond. ${ }^{8}$

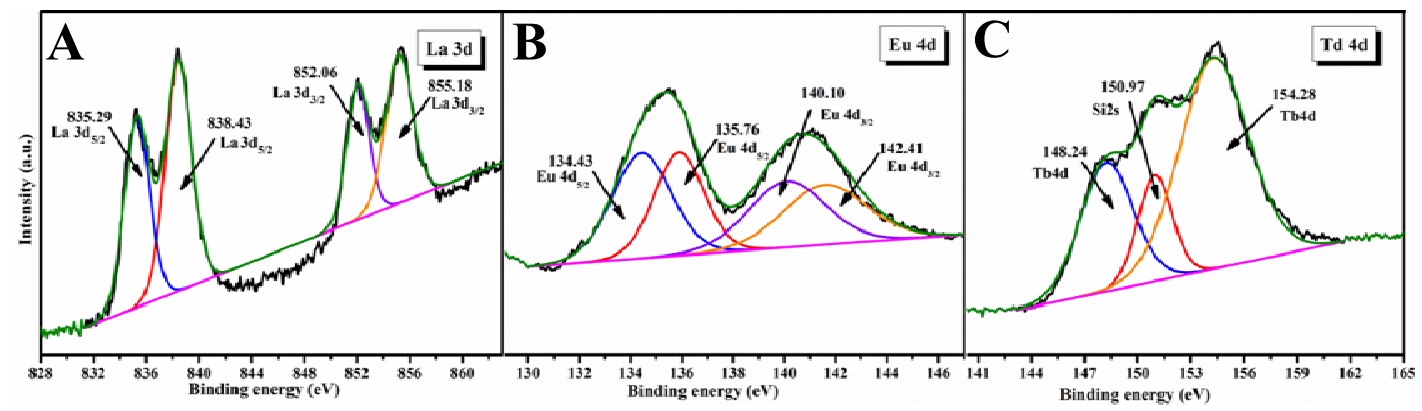

Figure S6. Core-level spectra of (A) La 3d, (B) Eu 4d and (C) Tb 4d after the adsorption of $\mathrm{Ln}^{3+}$ onto PAA-S HNFs. 


\section{References}

(1) Li, X.; Yu, X.; Cheng, C.; Deng, L.; Wang, M.; Wang, X. Electrospun Superhydrophobic Organic/Inorganic Composite Nanofibrous Membranes for Membrane Distillation. ACS Appl. Mater. Interfaces 2015, 7, 1337-1343.

(2) Zhang, W.; Shi, X.; Zhang, Y.; Gu, W.; Li, B.; Xian, Y. Synthesis of Water-Soluble Magnetic Graphene Nanocomposites for Recyclable Removal of Heavy Metal Ions. J. Mater. Chem. A $2013,1,1745-1753$.

(3) Wang, X.; Min, M.; Liu, Z.; Yang, Y.; Zhou, Z.; Zhu, M.; Chen, Y.; Hsiao, B. S. Poly(ethyleneimine) Nanofibrous Affinity Membrane Fabricated Via One Step Wet-Electrospinning from Poly(vinyl alcohol)-Doped Poly(ethyleneimine) Solution System and its Application. J. Membr. Sci. 2011, 379, 191-199.

(4) Huang, X.-Y.; Bin, J.-P.; Bu, H.-T.; Jiang, G.-B.; Zeng, M.-H. Removal of Anionic Dye Eosin Y from Aqueous Solution Using Ethylenediamine Modified Chitosan. Carbohydr. Polym. 2011, $84,1350-1356$.

(5) Irani, M.; Keshtkar, A. R.; Mousavian, M. A. Removal of Cd(II) and Ni(II) from Aqueous Solution by PVA/TEOS/TMPTMS Hybrid Membrane. Chem. Eng. J. 2011, 175, 251-259.

(6) Vijayaraghavan, K.; Yun, Y. S. Bacterial Biosorbents and Biosorption. Biotechnol. Adv. 2008, 26, 266-291.

(7) Moussavi, G.; Khosravi, R. Removal of Cyanide from Wastewater by Adsorption onto Pistachio Hull Wastes: Parametric Experiments, Kinetics and Equilibrium Analysis. J. Hazard. Mater. 2010, 183, 724-730. 
(8) Ouyang, J. M.; Zheng, W. J.; Huang, N. X.; Tai, Z. H. X-Ray Photoelectron Spectroscopy Study of Langmuir-Blodgett Films of N-octadecyl-8-hydroxy-2-quinoline Carboxamide Deposited from Subphases Containing Metal Ions. Thin Solid Films 1999, 340, 257-261.

(9) Freyria, F. S.; Barrera, G.; Tiberto, P.; Belluso, E.; Levy, D.; Saracco, G.; Allia, P.; Garrone, E.; Bonelli, B. Eu-Doped $\alpha-\mathrm{Fe}_{2} \mathrm{O}_{3}$ Nanoparticles with Modified Magnetic Properties. J. Solid State Chem. 2013, 201, 302-311.

(10) Kumar, S.; Prakash, R.; Kumar, V.; Bhalerao, G. M.; Choudhary, R. J.; Phase, D. M. Surface and Spectral Studies of $\mathrm{Eu}^{3+}$ Doped $\alpha-\mathrm{Al}_{2} \mathrm{O}_{3}$ Synthesized Via Solution Combustion Synthesis. Adv. Powder Technol. 2015, 26, 1263-1268.

(11) Qu, D.; Xie, F.; Meng, H.; Gong, L.; Zhang, W.; Chen, J.; Li, G.; Liu, P.; Tong, Y. Preparation and Characterization of Nanocrystalline $\mathrm{CeO}_{2}-\mathrm{Tb}_{2} \mathrm{O}_{3}$ Films Obtained by Electrochemical Deposition Method. J. Phys. Chem. C 2010, 114, 1424-1429.

(12) An, X.; Wang, Y.; Deng, J.; Chen, J.; Xing, X. Large Scale and Fast Synthesis of Multiferroic $\mathrm{TbMn}_{2} \mathrm{O}_{5}$ Single-Crystalline Nanorods. Mater. Res. Bull. 2014, 51, 74-79. 